\title{
Unexpected diagnosis of appendicitis in a paediatric patient with febrile neutropaenia and acute myeloid leukaemia
}

\author{
Christina Killian-Benigno, Dennis John Kuo
}

Division of Pediatric Hematology-Oncology, University of California, San Diego, California, USA

Correspondence to Dr Dennis John Kuo, dekuo@ucsd.edu

Accepted 1 July 2017
CrossMark

To cite: Killian-Benigno C, Kuo DJ. BMJ Case Rep Published Online First: [please include Day Month Year]. doi:10.1136/bcr-2017 221361

\section{DESCRIPTION}

A 3-year-old boy with M7 acute myeloid leukaemia was admitted for induction chemotherapy with cytarabine, daunorubicin and etoposide. Two days later, he developed febrile neutropaenia and was started on cefepime. Blood cultures showed no growth and the fevers abated. Three weeks later, while still neutropaenic and receiving cefepime, the fevers recurred and persisted for 3 days with a maximum fever of $39.8^{\circ}$ C. Antibiotics were changed to vancomycin and meropenem. He was non-toxic appearing without localising symptoms. He had occasional decreased appetite and loose stools, but he did not have abdominal pain, tenderness, masses or vomiting.

Due to the persistent fevers, a CT scan of the chest, abdomen and pelvis was ordered which showed an acute appendicitis with abscess formation (figure 1). Appendectomy demonstrated acute necrotising appendicitis on pathological review without evidence of leukaemic involvement. He recovered well and became afebrile. Eight days later, fevers without abdominal symptoms recurred. Repeat CT scanning showed a large abscess in the right lower quadrant (figure 2). This was subsequently drained and cultures grew Pseudomonas. He received cefepime, metronidazole, tobramycin and filgrastim and subsequently recovered. He was discharged home when his neutrophil counts recovered 11 days later.

The images shown demonstrate how large intra-abdominal processes can hide in the patient with neutropaenia. Due to the neutropaenia and lack of inflammatory immune responses, typical peritoneal signs were absent. His benign abdominal examination and continued oral intake were not suggestive of an intra-abdominal process at either time point, and

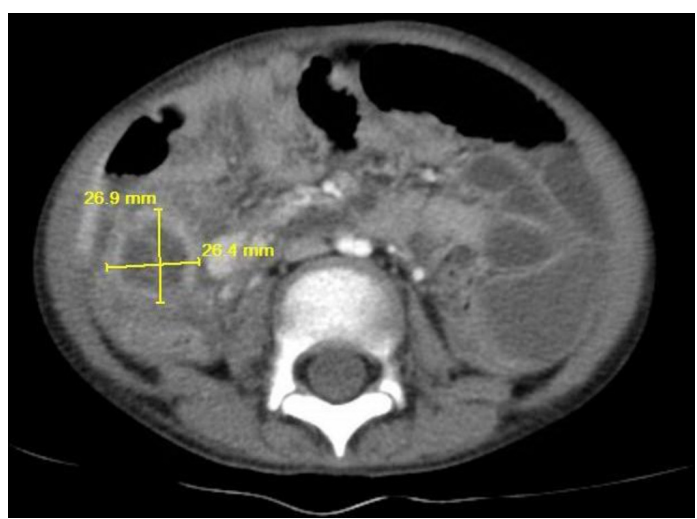

Figure 1 CT scan showing acute appendicitis with abscess formation.

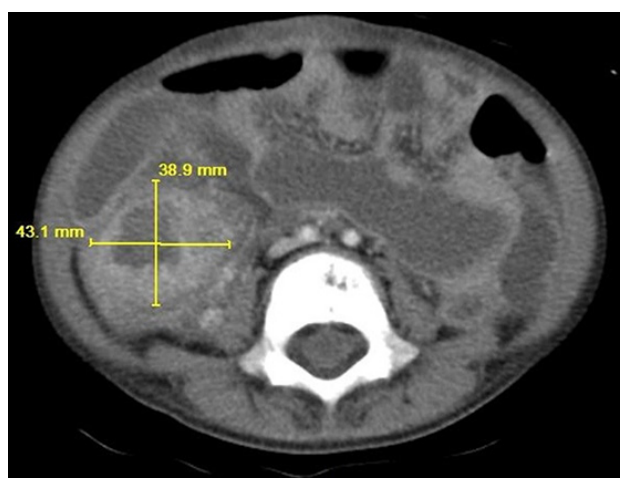

Figure 2 CT scan showing an abscess in the right lower quadrant.

without timely imaging, these infections could have progressed.

\section{Learning points}

- Intra-abdominal processes such as typhilitis, enterocolitis and appendicitis can be lifethreatening complications in patients with neutropaenia necessitating early diagnosis and intervention. ${ }^{12}$

- In a patient with neutropaenia, such as one receiving intensive chemotherapy for leukaemia, persistent fevers despite broadspectrum intravenous antibiotic administration can warrant imaging, particularly of the abdomen and pelvis, because prolonged neutropaenia can mask the localising signs of infection by decreasing the inflammation that produces pain. In this case, dramatic imaging findings were found despite minimal abdominal symptoms. ${ }^{3}$

Contributors CK and DJK both contributed to the conception writing, editing and submission of this manuscript.

Competing interests None declared.

Patient consent Obtained from guardian.

Provenance and peer review Not commissioned; externally peer reviewed.

(c) BMJ Publishing Group Ltd (unless otherwise stated in the text of the article) 2017. All rights reserved. No commercial use is permitted unless otherwise expressly granted.

\section{REFERENCES}

1 Mortellaro VE, Juang D, Fike FB, et al. Treatment of appendicitis in neutropenic children. J Surg Res 2011;170:14-16. 


\section{Images in...}

2 Warad D, Kohorst MA, Altaf S, et al. Acute appendicitis in acute leukemia and the potential role of decitabine in the critically ill patient. Leuk Res Rep 2015;4:21-3.
3 Gray TL, Ooi CY, Tran D, et al. Gastrointestinal complications in children with acute myeloid leukemia. Leuk Lymphoma 2010;51:768-77.

Copyright 2017 BMJ Publishing Group. All rights reserved. For permission to reuse any of this content visit

http://group.bmj.com/group/rights-licensing/permissions.

BMJ Case Report Fellows may re-use this article for personal use and teaching without any further permission.

Become a Fellow of BMJ Case Reports today and you can:

- Submit as many cases as you like

- Enjoy fast sympathetic peer review and rapid publication of accepted articles

- Access all the published articles

- Re-use any of the published material for personal use and teaching without further permission

For information on Institutional Fellowships contact consortiasales@bmjgroup.com

Visit casereports.bmj.com for more articles like this and to become a Fellow 